\title{
CONSUMO DE NUTRIENTES, DIGESTIBILIDADE IN VIVO E IN VITRO DE DIETAS PARA CÃES CONTENDO POLPA DE CITRUS E FOLHA DE ALFAFA
}

\author{
NUTRIENT INTAKE, IN VIVO AND IN VITRO DIGESTIBILITY OF DOG DIETS CONTAINING \\ CITRUS PULP AND ALFALFA LEAFT
}

\author{
Maria Isabel Fonseca Rocha Malafaia ${ }^{1}$ Emiliano de Aguiar Pedrozo ${ }^{1}$ José Amauri Pereira dos Santos ${ }^{1}$ \\ Marinaldo Divino Ribeiro ${ }^{2}$ Pedro Malafaia ${ }^{3}$ Ângela Maria Quintão Lana ${ }^{4}$
}

RESUMO

\begin{abstract}
Determinaram-se os consumos de nutrientes $e$ a digestibilidade aparente, in vivo e in vitro, em dez cadelas submetidas a uma dieta controle (RO) acrescida de 10 (R10) e 20\% (R20) de uma mistura contendo polpa de citros (PC) e folhas de feno de alfafa. A digestibilidade foi estimada pela coleta total de fezes e pelo uso das cinzas insolúveis em ácido. Quando expressos em \% do peso vivo, os consumos de água, de matéria seca (MS), de matéria orgânica (MO) e de proteína bruta $(P B)$ diminuiram à medida que os níveis de fibra aumentaram. Entretanto, a digestibilidade da MS, da PB, da fibra em detergente neutro $(F D N)$ e do extrato etéreo (EE) aumentou com o acréscimo do consumo das fontes fibrosas. A digestibilidade estimada pelos dois métodos resultou em valores cuja diferença não ultrapassou 5 unidades. Houve diferenças nos valores de digestibilidade in vitro quanto à origem do inóculo fecal e os maiores valores foram para as amostras dos ingredientes fibrosos incubados com inóculo oriundo dos animais que estavam ingerindo as dietas contendo as fontes de fibra. A polpa de citros resultou na maior digestibilidade in vitro, enquanto que a ração controle, na menor.
\end{abstract}

Palavras-chave: cães, digestão, intestinos, fibra dietética, polpa de citros.

\section{SUMMARY}

The determination of nutrient intake and the apparent in vivo and in vitro digestibilities in bitches fed a control ration (RO) or the same control ration containing $10 \%$ (R10) or 20\% (R20) of a mixture composed of citrus pulp (PC) and alfalfa hay leaft, were the objective of this study. The digestibility was estimated by total feaces collection and by the use of the ash insoluble in acid. When expressed in $\%$ of liveweight, the intake of water, dry matter (DM), organic matter $(O M)$ and crude protein $(C P)$ were reduced as the fiber levels increased. However, DM, CP, neutral detergent fiber (NDF) and ether extract (EE) digestibilities increased as the fiber levels increased in the diets. The digestibility values estimated by these two methods were different, but not greater than 5 units. The source of fecal inocula resulted in different values for in vitro digestibility, and the inocula of the animals consuming the fiber sources gave the highest results. The citrus pulp was the component which presented the greatest in vitro digestibility whereas the control diet gave the lowest values for in vitro digestibility.

Key words: citrus pulp, digestion, dogs, dietary fiber, intestine.

\section{INTRODUÇÃO}

Sabe-se que o gênero Homo viveu aproximadamente $99,93 \%$ de sua história evolutiva sem o convívio com animais domesticados (HOFMANN, 1991). Certamente o primeiro animal a ser domesticado foi do gênero Canis e, inicialmente, esses animais ingeriam as sobras da alimentação dos hominídeos. A alimentação dos cães, dessa forma, permaneceu até meados do século XIX, quando em 1860, James Spratt idealizou e comercializou pela primeira vez um preparado alimentar seco para cães (CASE et al., 1995).

Entretanto, com o passar dos anos, a ciência da nutrição canina desenvolveu-se e rações com níveis adequados de nutrientes para as diversas classes de tamanho do corpo e fases do ciclo vital foram lançadas no mercado. Uma ração balanceada deve conter

\footnotetext{
${ }^{1}$ Médicos Veterinários, Universidade Federal Rural do Rio de Janeiro (UFRRJ), 23851-970, Seropédica, RJ.

${ }^{2}$ Zootecnista, UFRRJ

${ }^{3}$ Zootecnista, Doutor, Professor Adjunto, UFRRJ-IZ-DNAP, 23851-970, Seropédica, RJ. Bolsista do CNPq.E-mail: malafeia@ufrrj.br. Autor para correspondências

${ }^{4}$ Engenheiro Agrônomo, Doutor, Professor Adjunto, UFRRJ/DMAT. 
ingredientes cuja digestibilidade seja elevada, o que resulta em maior aporte de nutrientes para atender à demanda dos tecidos do animal. Dessa maneira, a digestibilidade constitui parâmetro importante na avaliação de rações para cães.

Até meados da década de 70 , os constituintes da parede celular vegetal (CPCV), também denominados de fibra, foram descritos como componentes inertes nas rações de animais carnívoros e omnívoros (EHLE et al., 1982). Entretanto, após inúmeras publicações, essa idéia foi repensada, especialmente no que diz respeito à ação benéfica desses $\mathrm{CPCV}$ na saúde do epitélio intestinal, na redução dos níveis intestinais de amônia e de outras substâncias tóxicas, na facilidade para defecação e na taxa de passagem da digesta pelo trato gastrintestinal (McDOUGALL

et al., 1996). Apesar desses efeitos benéficos, a adição de fontes de CPCV, especialmente as ligno-celulósicas, nas dietas para animais não-ruminantes pode causar redução na digestibilidade dos nutrientes (Van SOEST, 1994). Estudos mais detalhados sobre a interação negativa da fibra com a digestibilidade em rações para cães, resultaram na idéia que a adição de fontes de fibra de moderada fermentabilidade intestinal traria os efeitos benéficos descritos acima e não causaria redução na digestibilidade dos nutrientes (FAHEY et al., 1992; SUNVOLD et al., 1995).

Do exposto, os objetivos, com esse experimento, foram estimar o consumo de nutrientes e determinar a digestibilidade aparente in vivo e in vitro de dietas contendo diferentes níveis de polpa de citros e de folha de alfafa para cães adultos em regime mantença.

\section{MATERIAL E MÉTODOS}

O experimento foi montado em um delineamento inteiramente casualizado, utilizando-se dez cadelas SRD, não castradas, vermifugadas, com peso vivo médio inicial de $10,10 \mathrm{~kg}$, com idade média entre dois e três anos, alojadas individualmente em baias cimentadas, conforme recomendações da ASSOCIATION OF AMERICAN FEED CONTROL OFFICIALS (AFFCO, 1999). Cada período experimental constou de 35 dias, sendo 28 para adaptação às condições experimentais e sete para a coleta de dados. Durante o período de adaptação, os animais foram pesados semanalmente e então levados para receber o sol da manhã e se exercitarem.

Foram utilizadas três dietas (Tabela 1) isoprotéicas $(23,64 \%$ de PB na base da matéria seca), utilizando-se uma ração controle (R0), à qual se adicionou $10 \%$ (R10) ou 20\% (R20) de fontes de fibra. As fontes de fibra utilizadas foram a polpa de citros (PC) e a folha de alfafa desidratada (FA), misturadas previamente em partes iguais. Este último material, obtido a partir do feno de alfafa comercial, que foi manualmente separado entre caules (desprezados) e folhas (FA). A mistura de $50 \%$ de PC e $50 \%$ de FA objetivou a obtenção de uma fonte de fibra de moderada fermentação intestinal. A ração controle era comercializada rotineiramente nas lojas como ração para cães adultos em regime de mantença. As dietas foram fornecidas duas vezes ao dia, às $8(40 \%)$ e às 16 horas (60\%), sempre observando sobras de aproximadamente $10 \%$. Antes de serem ministradas aos animais, as dietas foram previamente umectadas com $100 \mathrm{~m} \ell$ de água morna. Os animais tiveram livre acesso à água fresca durante todo o período experimental; entretanto, apenas na fase de coleta, foram feitas medições do consumo diário individual. $\mathrm{O}$ consumo total de água foi obtido como sendo a soma do volume de água fornecido junto com as dietas e aquele bebido no dia.

As amostragens das dietas, bem como das sobras da alimentação de cada animal foram realizadas diariamente nas fases de adaptação e de coleta. Esses materiais foram conservados $\mathrm{a}-5^{\circ} \mathrm{C}$. Ao final de cada semana, as amostras individuais foram homogeneizadas e deram origem a uma amostra composta para cada um desses materiais. No período de coleta, individualmente, e em cada defecação, as fezes, eram imediatamente pesadas e armazenadas a $5^{\circ} \mathrm{C}$ até serem pré-secas, à $55^{\circ} \mathrm{C}$ por 72 horas em estufa de ventilação forçada. Após a pré-secagem, todos os 
materiais foram moídos para atingirem granulometria de $2 \mathrm{~mm}$. Foram feitas determinações (nas dietas, na polpa de citros, na folha de alfafa e nas fezes) de fibra em detergente neutro (FDN) (Van SOEST et al.,1991), cinzas insolúveis em ácido (CIA) (ROWAN et $\boldsymbol{a l}$., 1991), energia bruta (EB), matéria seca (MS), extrato etéreo (EE) e proteína bruta (PB), segundo a ASSOCIATION OF OFFICIAL ANALYTICAL CHEMISTS (AOAC, 1990). A estimativa da digestibilidade aparente foi feita pelo sistema de coleta total e pela utilização das cinzas insolúveis em ácido (CIA) como indicador. A composição bromatológica das dietas experimentais encontra-se na tabela 1.

Para estimar a digestibilidade in vitro, foram realizadas incubações da dieta controle, da polpa de citros e da folha de alfafa. Inicialmente, pesaram-se $0,5 \mathrm{~g}$ de cada amostra, que foram dispostas separadamente em dois Erlemeyers de $125 \mathrm{~m} \ell$. O inóculo microbiano intestinal foi obtido imediatamente após ser defecado pelos animais. A amostra fecal, récem-defecada, contendo a biomassa microbiana foi transportada na temperatura de $39^{\circ} \mathrm{C}$ para o laboratório $\mathrm{e}$, ao chegar, foram pesadas $70 \mathrm{~g}$ desse material fecal e adicionadas à $1000 \mathrm{~m} \ell$ do meio de cultura previamente saturado com $\mathrm{CO}_{2}$, reduzido com $\mathrm{HCl}$-cisteina (625mg) $+\mathrm{Na}_{2} \mathrm{~S}\left(625 \mathrm{mg}\right.$ ) e mantido a $39^{\circ} \mathrm{C}$ (LONGLAND et al. , 1995). Após então, adicionou-se aos Erlemeyers, seguindo técnicas de anaerobiose, $40 \mathrm{~m} \ell$ deste meio contendo a microbiota intestinal. Após 30 horas de incubação, os Erlemeyers foram retirados do banhomaria $\left(39^{\circ} \mathrm{C}\right)$ e seu conteúdo filtrado em cadinho filtrante de porosidade zero pré-pesado; após esse procedimento, os cadinhos foram colocados em estufa à $105^{\circ} \mathrm{C}$ por 12 horas e então pesados para se estimar a digestibilidade in vitro (MALAFAIA et al., 1997). Para detectar possíveis diferenças nos valores das digestibilidades devido às alterações dietéticas (presença ou não de fibra adicional), foram realizadas incubações com material fecal oriundo dos animais controle e dos animais R20.

As médias dos consumos diários e da digestibilidade aparente dos nutrientes, foram analisadas por intermédio da utilização do teste "T" para dados pareados, assumindo-se $5 \%$ de probabilidade.

\section{RESULTADOS E DISCUSSÃO}

A ingestão das fontes fibrosas causou a redução do consumo de água, expresso em $\mathrm{g} / \mathrm{kg}$ peso vivo e em $\%$ do peso vivo (Tabela 2). Tal fato, provavelmente, pode ser explicado pela maior capacidade de retenção de água pelos diferentes componentes da parede celular vegetal (Van SOEST, 1994). Esta maior retenção causa uma hidratação no lúmen intestinal, podendo reduzir a necessidade hidrica diária. O consumo de água e dos outros nutrientes, em $\mathrm{kg} / \mathrm{dia}$, deve ser interpretado com cautela uma vez que no início do experimento os animais tinham 10,11 quilos e, ao final do estudo, possuíam 11,45 quilos, mesmo sendo animais adultos e, teoricamente, recebendo um regime de mantença. $\mathrm{O}$ consumo de água, expresso em g de água/gMS ingerida, se situa entre 2 e 3 vezes o consumo de MS (NRC, 1985). Essas recomendações são empíricas e servem apenas para se ter idéia da quantidade de água a ser fornecida diariamente aos animais. Neste estudo, o consumo de água foi de 2,03 (dieta controle); 1,78 (R10) e 1,75 (R20) g/g de MS ingerida; portanto, à exceção da dieta controle, o consumo de água foi menor do que o estabelecido no manual do NRC (1985). O consumo de MS, em g/kgPV e em \% do PV, diminuiu significativamente $(\mathrm{P}<0,05)$ com o aumento do consumo das fontes de fibra (Tabela 2). Este fato pode estar associado ao acréscimo na digestibilidade da MS (Tabela 3). A ingestão de aproximadamente 3\% do

Tabela 2 - Consumos médios diários de Água, Matéria Seca (MS), Matéria Orgânica (MO), Proteína Bruta (PB), Fibra em Detergente Neutro $($ FDN) e Extrato Etéreo (EE) avaliadas em cadelas.

\begin{tabular}{|c|c|c|c|c|c|c|c|c|c|}
\hline & \multicolumn{3}{|c|}{ Consumo (kg/dia) } & \multicolumn{3}{|c|}{ Consumo (g/kg PV) } & \multicolumn{3}{|c|}{ Consumo (\% PV) } \\
\hline & $\begin{array}{c}\text { Dieta } \\
\text { controle }\end{array}$ & $\begin{array}{c}\text { Dieta com } \\
10 \% \text { de } \\
\text { fibra }\end{array}$ & $\begin{array}{l}\text { Dieta com } \\
20 \% \text { de } \\
\text { fibra }\end{array}$ & $\begin{array}{c}\text { Dieta } \\
\text { controle }\end{array}$ & $\begin{array}{c}\text { Dieta com } \\
10 \% \text { de } \\
\text { fibra }\end{array}$ & $\begin{array}{l}\text { Dieta com } \\
20 \% \text { de } \\
\text { fibra }\end{array}$ & $\begin{array}{c}\text { Dieta } \\
\text { controle }\end{array}$ & $\begin{array}{c}\text { Dieta com } \\
10 \% \text { de } \\
\text { fibra }\end{array}$ & $\begin{array}{l}\text { Dieta } \\
\text { com } 20 \% \\
\text { de fibra }\end{array}$ \\
\hline Água & $0,656^{\mathrm{a}}$ & $0,568^{\mathrm{c}}$ & $0,601^{\mathrm{b}}$ & $64,9^{\mathrm{a}}$ & $55,12^{\mathrm{b}}$ & $52,54^{\mathrm{c}}$ & $6,49^{\mathrm{a}}$ & $5,51^{\mathrm{b}}$ & $5,25^{\mathrm{c}}$ \\
\hline MS & $322,6^{\mathrm{b}}$ & $318,8^{\mathrm{c}}$ & $343,4^{\mathrm{a}}$ & $31,9^{\mathrm{a}}$ & $30,9^{\mathrm{b}}$ & $30,0^{\mathrm{c}}$ & $3,19^{\mathrm{a}}$ & $3,09^{\mathrm{b}}$ & $2,99^{\mathrm{c}}$ \\
\hline MO & $293,2^{b}$ & $287,1^{\mathrm{c}}$ & $306,4^{\mathrm{a}}$ & $28,9^{\mathrm{a}}$ & $27,6^{\mathrm{b}}$ & $26,5^{\mathrm{b}}$ & $2,89^{\mathrm{a}}$ & $2,76^{\mathrm{b}}$ & $2,65^{\mathrm{b}}$ \\
\hline PB & $77,6^{\mathrm{b}}$ & $76,0^{\mathrm{b}}$ & $79,4^{\mathrm{a}}$ & $7,7^{\mathrm{a}}$ & $7,4^{\mathrm{a}}$ & $7,0^{\mathrm{b}}$ & $0,77^{\mathrm{a}}$ & $0,75^{\mathrm{a}}$ & $0,71^{\mathrm{b}}$ \\
\hline FDN & $66,4^{\mathrm{c}}$ & $69,7^{\mathrm{b}}$ & $79,5^{\mathrm{a}}$ & $6,5^{\mathrm{c}}$ & $6,7^{b}$ & $6,9^{\mathrm{a}}$ & $0,65^{\mathrm{c}}$ & $0,67^{\mathrm{b}}$ & $0,69^{\mathrm{a}}$ \\
\hline $\mathrm{EE}$ & $20,22^{\mathrm{a}}$ & $19,38^{\mathrm{a}}$ & $18,92^{\mathrm{a}}$ & $2,0^{\mathrm{a}}$ & $1,9^{\mathrm{a}}$ & $1,8^{\mathrm{a}}$ & $0,21^{\mathrm{a}}$ & $0,19^{\mathrm{a}}$ & $0,18^{\mathrm{a}}$ \\
\hline
\end{tabular}

Médias na mesma linha com letras diferentes, diferem em nível de $5 \%$ pelo teste "T".

Ciência Rural, v. 32, n. 1, 2002. 
Tabela 3 - Digestibilidades aparentes da Matéria Seca (MS), Mátéria Orgânica (MO), Proteína Bruta (PB), Fibra em Detergente Neutro (FDN), Extrato Etéreo (EE) e da Energia Bruta (EB) avaliados em cadelas.

\begin{tabular}{lcccccc}
\hline \multicolumn{2}{c}{ Digestibilidade - coleta total (\%) } & Digestibilidade - Cinzas insolúveis \\
em ácido ( \% )
\end{tabular}

Médias na mesma linha com letras diferentes, diferem em nível de $5 \%$ pelo teste "T".
0,44\% PV) e por FAHEY et al., em 1992 $(0,36-0,40 \% \mathrm{PV})$. Entretanto, as dietas utilizadas naqueles estudos continham 24,2 e $17,7 \%$ de gordura, respectivamente.

A ingestão diária de energia metabolizável foi de 1128,6, 1101,1 e de $1169,1 \mathrm{kcal}$ para os animais que ingeriram a dieta controle, R10 e R20, respectivamente. Esses valores, expressos em kcal de EM/gMS ingerida foram de 3,$49 ; 3,45$ e 3,40 e, são inferiores ao valor 4,68 descrito por SUNVOLD et al., em 1995, para uma dieta contendo $7,5 \%$ de polpa de citros. Essa diferença é explicada pela qualidade superior da dieta experimental utilizada naquele estudo, que era do tipo "super premium" com 82,3\% de digestibilidade da MS. Valores entre

peso vivo, é maior do que a descrita por FAHEY et al., em 1990a (2,72 - 2,79\%PV) e em 1992 (1,98 2,35\%PV), por SUNVOLD et al., em 1995 (1,52 1,96\%PV) e por MURRAY et al., em 1997 (1,53 $1,94 \% \mathrm{PV})$. Estas diferenças podem ser oriundas do fato de que os animais, naqueles estudos, recebiam dietas tipo "super-premium", cuja digestibilidade normalmente excede a $83 \%$. Dessa maneira, tal comparação é relativa. A ingestão de $\mathrm{PB}$, em gramas por dia, foi maior $(\mathrm{P}<0,05)$ para a dieta R20 (Tabela 2), mesmo sendo os tratamentos isoprotéicos (Tabela 1). Entretanto, quando analisada em $\%$ do peso vivo, a dieta R20 foi a que proporcionou o menor consumo de $\mathrm{PB}$, uma vez que os animais ganharam peso. Esses dados, quando comparados com os observados em outros estudos são bastante discrepantes. Na literatura consultada, foram encontrados valores entre 0,33 e 0,38\% PV (MURRAY et al., 1997), 0,83 e 0,90\% PV (FAHEY et al., 1992) e 0,65 e 0,74\% PV (FAHEY et al., 1992). Essas diferenças podem ser explicadas também devido ao tipo de dieta utilizada naqueles estudos, que eram todas do tipo "super-premium".

O consumo de FDN aumentou significativamente à medida que houve a inclusão das fontes de fibra nas dietas (Tabela 2). Embora não exista uma exigência de "FDN" para a espécie canina, a ingestão desta entidade analítica vem sendo descrita em alguns artigos. Valores de 63,8 e 79,7g/dia foram descritos por FAHEY et al., em 1990b, para animais comendo dietas contendo 10 e $12,5 \%$ de polpa de beterraba. Esses valores são semelhantes aos observados neste experimento.

Os consumos diários de EE não diferiram entre os tratamentos (Tabela 2), e foram inferiores aos descritos por SUNVOLD et al., em 1995 (0,34 3,5 e 4,3kcal de EM/gMS consumida são obtidos quando se utiliza as recomendações do manual do NRC de 1985; portanto, os dados obtidos neste estudo estão próximos do limite inferior de 3,5 kcal de EM/gMS consumida.

As estimativas dos coeficientes de digestibilidade (CD) pela coleta total de fezes e pela utilização das cinzas insolúveis em ácido (CIA), diferiram significativamente $(\mathrm{P}<0,05)$ para todas as determinações; exceto para os CD da FDN da dieta controle e do EE da dieta R20 (Tabela 3). Mesmo havendo diferença entre esses métodos, esta foi menor do que 5 unidades de digestibilidade e as estimativas tiveram o mesmo comportamento daquela observada para a coleta total. Estes fatos podem ser úteis na escolha de um indicador para estudos de digestibilidade em cães, à semelhança do verificado por JOHNSON $\boldsymbol{e t}$ $\boldsymbol{a l}$., em 1998, no qual a utilização das CIA resultou em valores mais verossímeis do que o $\mathrm{Cr}_{2} \mathrm{O}_{3}$. Neste estudo, a recuperação fecal das CIA foi de $113,1 \%$ para a ração controle, $113,6 \%$ para a R10 e 109,2\% para a R20. Os valores superiores a $100 \%$ são oriundos, provavelmente, da marcha analítica empregada para analisar as CIA que ainda resultam em baixa repetibilidade entre as repetições laboratoriais.

Os valores dos CD encontrados para a MS diferiram entre os tratamentos e foram maiores à medida que os animais passaram a ingerir as dietas contendo as fontes de fibra (Tabela 3). A literatura sobre o assunto é conflitante pois, em alguns estudos, ocorreram aumento da digestibilidade (SUNVOLD $\boldsymbol{e} t$ $\boldsymbol{a l} .$, 1995) e em outros, ocorreram redução (FAHEY $\boldsymbol{e t}$ al., 1990a, 1990b e 1992). A explicação para essas diferenças reside na fonte de fibra utilizada. Os estudos que utilizaram fontes de fibra com maior teor de lignocelulose, os $\mathrm{CD}$ reduziram e, naqueles que empregaram fontes abundantes em pectina, os $\mathrm{CD}$ se 
equivaleram ou até mesmo melhoraram (VINIK \& JENKINS, 1988; TITGEMEYER et al., 1991). Valores observados em outros estudos são de relativa importância para comparação; uma vez que são oriundos de dietas "super premium" (FAHEY $\boldsymbol{e t}$ al., 1990a, 1990b e 1992; SUNVOLD et al., 1995).

A adição das fontes fibrosas melhorou a digestibilidade aparente da MO, da PB, do EE e da FDN (Tabela 3). Provavelmente, este fato se deve ao maior tempo de trânsito (12 horas para a R20 e 8 horas para a R0) causado pela ingestão da fonte de fibra utilizada neste estudo (PEDROZO et al., 2001). As fontes de fibra com maior teor de substâncias pécticas promovem maior retenção da digesta (VAN SOEST, 1994) e, com uma maior retenção, maior digestibilidade pode ser verificada.

Os valores de digestibilidade da FDN para a dieta controle (R0) e para a R10, foram menores do que aqueles verificados para outras fontes de fibra utilizadas por FAHEY et al. (1990a, 1990b e 1992). Valores entre $35,5 \%$ (polpa de tomate), 36,9\% (casca de amendoim) 39,4\% (polpa de beterraba) e 41,6\% (farelo de trigo) foram descritos por aquele autor em 1990b. Apenas o CD da FDN da dieta R20 foi similar aos verificados por FAHEY et al. (1990b).

O limite máximo da digestão da MS em 30 horas de incubação in vitro foi maior para a dieta controle (R0), quando incubada com inóculo fecal oriundo dos animais que não comiam as fontes de fibra (Tabela 4). Provavelmente, nos animais que comeram as fontes de fibra, alterações na microbiota que fermenta os carboidratos não estruturais pode ter sido a causa da menor digestão da dieta R0, quando incubada com inóculo desses animais. Para a polpa de citros e a folha de alfafa, também houve diferenças entre as fontes de inóculo fecal. Isto significa que a avaliação de fontes de fibra in vitro requer uma prévia alimentação dos animais com dietas contendo a fonte a ser investigada.

Os valores encontrados para a digestibilidade in vitro da polpa de citros são 13 unidades de digestibilidade inferiores aos relatados por

Tabela 4 - Digestibilidade aparente em 30 horas de fermentação in vitro da Matéria Seca (MS) avaliadas em cadelas.

\begin{tabular}{lcc}
\hline & $\begin{array}{c}\text { Inóculo dos animais } \\
\text { controle }\end{array}$ & $\begin{array}{c}\text { Inóculo dos animais que } \\
\text { comiam a dieta com } \\
20 \% \text { de fibra }\end{array}$ \\
\hline Dieta controle & $56,1^{\text {a }}$ & $50,8^{\mathrm{b}}$ \\
Polpa de citros & $65,2^{\mathrm{b}}$ & $67,3^{\mathrm{a}}$ \\
Folha de Alfafa & $39,6^{\mathrm{b}}$ & $43,2^{\mathrm{a}}$ \\
\hline
\end{tabular}

Médias na mesma linha com letras diferentes, diferem em nível de $5 \%$ pelo teste "T".
REINHARDT \& SUNVOLD em 1996; entretanto, neste estudo, incubou-se um alimento, enquanto que aquele autor utilizou uma fonte purificada de pectina cítrica, que, por ser em forma de pó, facilitou o acesso microbiano ao substrato e à perda de amostra do resíduo indigerível durante a fase de filtração. Tais aspectos podem ter proporcionado maior digestibilidade in vitro verificada naquele estudo.

\section{CONCLUSÕES}

Conforme verificado neste estudo, a inclusão de fontes de fibra de moderada fermentabilidade reduz a ingestão de água, de Matéria Seca, de Matéria Orgânica e de Proteína Bruta, expressos em porcentagem do peso vivo dos animais. A digestibilidade da Matéria Seca, da Proteína Bruta, do Extrato Etéreo e da Fibra em Detergente Neutro, melhora à medida que o nível de fibra dietético aumenta. As estimativas dos coeficientes de digestibilidade não resultam em valores similares para a técnica de coleta total de fezes ou para técnica das cinzas insolúveis em ácido. A digestibilidade in vitro é maior para as amostras fibrosas incubadas com inóculo oriundo dos animais que ingerem as dietas contendo essas fontes. Dentre os alimentos incubados, a polpa de citros apresenta o maior coeficiente de digestibilidade in vitro. A técnica in vitro é mais rápida, barata e adequada para discriminar as diferenças entre alimentos para a espécie canina.

\section{REFERÊNCIAS BIBLIOGRÁFICAS}

ASSOCIATION OF AMERICAN FEED CONTROL OFFICIALS (AFFCO). Official Publication. Atlanta, 1999. $162 \mathrm{p}$.

ASSOCIATION OF OFFICIAL ANALYTICAL CHEMISTS. (AOAC). Official methods of analysis. 15 ed. Arlington, 1990, v.1, 1117p.

CASE, L.P.; CAREY, D.P.; HIRAKAWA, D.A. Canine and feline nutrition. Saint Louis : Mosby Year Book, 1995. 455p.

EHLE, F.R.; ROBERTSON, J.B.; VAN SOEST, P.J. Influence of dietary fibers on fermentation in the human large intestine. Journal of Nutrition, v.112, n.1, p.158-166, 1982.

FAHEY, G.C.; MERCHEN, N.R.; CORBIN, J.E., et al. Dietary fiber for dogs. I. Effects of graded levels of dietary beet pulp on nutrient intake, digestibility, metabolizable energy, and digesta mean retention time. Journal of Animal Science, v.68, n.8, p.4221-4228, 1990a.

FAHEY, G.C.; MERCHEN, N.R.; CORBIN, J.E., et al. Dietary fiber for dogs. II. Iso-total dietary fiber additions of divergent fiber sources to dog diets and their effects on nutrient intake, digestibility, metabolizable energy and digesta mean retention time. Journal of Animal Science, v.68, n.8, p.4229-4235, 1990 b. 
FAHEY, G.C.; MERCHEN, N.R.; CORBIN, J.E., et al. Dietary fiber for dogs. III. Effects of beet pulp and oat fiber additions to dog diets on nutrient intake, digestibility, metabolizable energy, and digesta mean retention time. Journal of Animal Science, v.70, n.4, p.1169-1174, 1992.

HOFMANN, R.R. Recents advances on the nutrition of herbivores Hannover : MSAP, 1991. Endangered tropical herbivores. Their nutritional requeriments and habitat demands: p.27.

JOHNSON, M.L.; PARSONS, C.M.; FAHEY, C.G., et al. Effects of species raw material source, ash content and processing temperature on aminoacid digestibility of animal by-product meals by cecectomized roosters and ileally cannulated dogs. Journal of Animal Science, v.76, n.6, p.1112-1122, 1998.

LONGLAND, A.C.; THEODOROU, M.K.; SANDERSON, R., et al. Non-Starch polysaccharide composition and in vitro fermentability of tropical forage legumes varying in phenolic content. Animal Feed Science and Technology, v.55, p.161-177, 1995 .

McDOUGALL, G.J.; MORRISON, I.M.; STEWART, D., $\boldsymbol{e}$ t al. Plant cell walls as dietary fiber: Range, Structure, Processing and function. Journal of Science Food and Agriculture, v.70, p.133-150, 1996.

MALAFAIA, P.A.M.; VIEIRA, R.A.M.; SILVA, D.O. In vitro degradation of coast-cross by rumen microorganims associated with Saccharomyces cerevisiae or Humicola sp. Revista de Microbiologia, v.28, n.4, p.261-267, 1997.

MURRAY, S.M.; PATIL, A.; FAHEY, C.G., et al. Raw and rendered by-product as ingredients in dog diets. Journal of Animal Science, v.75, n.8, p.2497-2505, 1997.

NATIONAL RESEARCH CONCIL (NRC). Nutrients requeriments of dogs. Washington, DC : National Academy of Science, 1985. p.123.
PEDROZO, E.A.; SANTOS, J.A.P.; MALAFAIA, M.I.F., $\boldsymbol{e}$ t al Aspectos morfométricos, fisiológicos e patológicos do tratogastrintestinal de cães ingerindo rações contendo diferentes níveis de fibra. Pesquisa Veterinária Brasileira, 2001, no prelo.

REINHART, G.A.; SUNVOLD, G.D. In vitro fermentation as a predictor of fiber utilization. In: CAREY,D.P.; NORTON, S.A.; BOLSER, S.M. Recent advances in canine and feline nutritional research. Wilmington, Ohio : Orange Frazer, 1996. Cap.3, p.15-24.

ROWAN, A.M.; MOUGHAN, P.J.; WILSON, M.N. Acidinsoluble ash as a marker compound for use in digestibility studies with humans. Journal of Science Food and Agriculture, v.54, n.2, p.269-274, 1991.

SUNVOLD, G.D.; FAHEY, G.C.; MERCHEN, N.R., $\boldsymbol{e}$ t al. Dietary fiber for dogs. IV. In Vitro fermentation of selected fiber sources by dog fecal inoculum and In Vivo digestion and metabolism of fiber-supplemented diets. Journal of Animal Science, v.73, n.6, p.1099-1109, 1995.

TITGEMEYER, E.C.; BOURQUIN, L.D.; FAHEY, G.C., et al. Fermentability of various fiber sources by human fecal bacteria in vitro. American Journal of Clinical Nutrition, v.53, n.3, p.1418-1427, 1991.

Van SOEST, P.J. Nutritional ecology of the ruminant. Ithaca : Cornell University, 1994. 474p.

Van SOEST, P.J.; ROBERTSON, J.B.; LEWIS, B.A. Methods for dietary fiber, neutral detergent fiber, and nonstarch polysaccharides in relation to animal nutrition. Journal of Dairy Science, v.74, n.10, p.3583-3597. 1991.

VINIK, A.I.; JENKINS, D.J.A. Dietary fiber in management of diabetes. Diabetes Care v.11, n.3, p.160-171, 1988. 